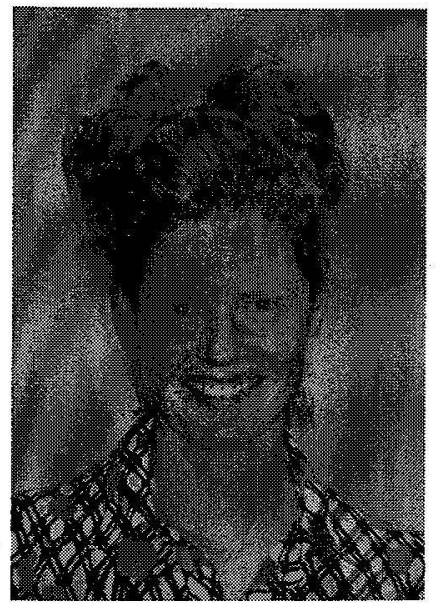

\title{
RESEARCH AND THE \\ POLICY DEVELOPMENT \\ PROCESS: "MEASURING \\ THE COSTS OF INJURY"1
}

\author{
Jaimie Legge \\ Labour Market Policy Group \\ Department of Labour
}

\begin{abstract}
This paper discusses the development of a methodology for measuring the costs of injury in New Zealand. This is work in progress, involving a number of researchers and government agencies with a goal of developing useful cost estimations of the impact of injury for policy development.
\end{abstract}

\section{Introduction}

This short paper outlines an inter-agency project that is being undertaken to improve our understanding of the nature of costs of injury in New Zealand, how this project will build on the Social and Economic Consequences Workplace Injury and Illness Research that has recently been undertaken by the Department of Labour, how this project will contribute to better policy outcomes, and the methodology proposed.

\section{What is the costs of injury project and how does it differ from the social consequences research?}

The costs of injury project is designed to improve information on the costs of injury in New Zealand, by quantifying - where possible-both the impact or consequences of injury on individuals and wider society, and their efforts to avoid or prevent the incidence and/or severity of injury.

A wide definition of costs to include economic and human costs of injury has initially been adopted for the project. "Economic costs" are taken to refer to the direct and indirect costs of injury: the publicly and privately funded costs associated with prevention, diagnosis, treatment and rehabilitation; and costs associate with the loss of productivity due to injury. "Human costs" are taken to refer to intangible costs such as pain and suffering and other psychosocial consequences of injury.

Many of these costs were identified through the Social and Economic Consequences of Workplace Injury and Illness Research. The costs of injury project attempts to take the findings of this research one step further by systematically quantifying, to the extent possible, these costs (and potentially other costs, such as those from injuries suffered outside the workplace) on a one-off basis and, hopefully, on an ongoing basis. The social consequences research will provide an invaluable input in terms of determining which costs elements are pertinent in New Zealand and therefore which costs elements to quantify.

In the costs of injury project a distinction (albeit subtle) has also been drawn between information and data-the project is not simply about improving data, but improving how existing data is used (that is, how that data needs to be manipulated to address specific policy questions).

\section{Why is the costs of injury project being undertaken and how will it contribute to improved policy outcomes?}

The main impetus for the Costs of Injury Project was the findings of the Injury Data Review (Review) ${ }^{2}$ and recent legislative reforms the ACC Scheme (the Injury Prevention, Rehabilitation, and Compensation Act 2001).

A key output of the Review was a Framework for Injury Data ("the Framework") to be implemented by Statistics New Zealand in their capacity as Injury Information Manager $^{3}$ (see Figure 1 below). In addition, the Review produced a range of indicators and a minimum dataset to inform each aspect of the Framework. These indicators and data-set are also to be implemented by the Injury Information Manager. 


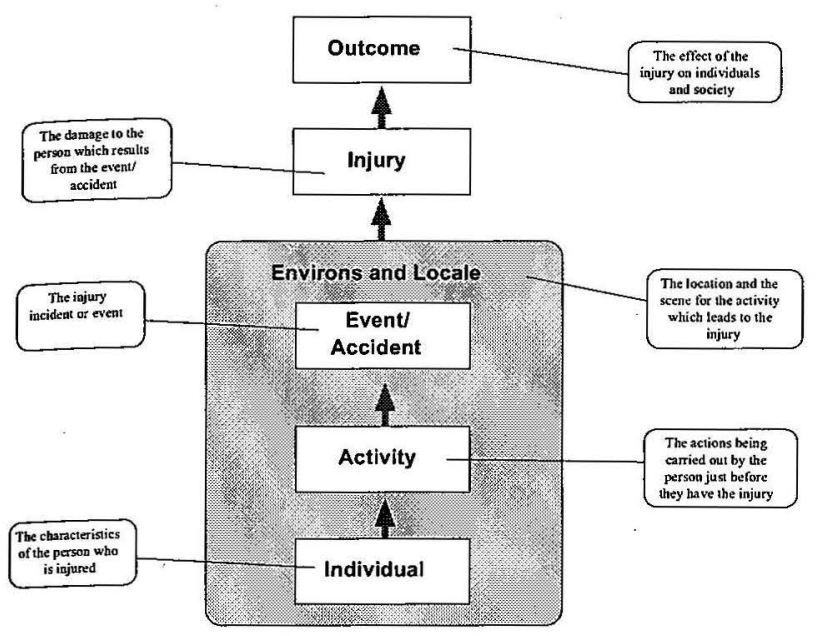

One of the findings of the Review was that there was inadequate data on the costs of injury. Injury costs data were considered, amongst other things, to be important indicators of "outcome" in the Framework, above, which was defined as the effect of injury on individuals and society. The specific injury costs variables identified in the Review were: cost of compensation (ACC data source), cost of treatment (ACC, NZHIS data sources), and cost of rehabilitation (ACC data source). These data were considered the minimum necessary to develop an indicator to inform the policy question: "what are the financial costs of injury?"

The premise made for the Costs of Injury project is that government agencies' injury cost information needs are more complex than this specific question, and that it is possible to articulate the data requirements to address this and a much wider range of policy questions.

Our initial, high-level analysis of government's costs of injury information needs supports this premise. Some examples include:

- With the New Zealand Injury Prevention Strategy ${ }^{4}$, cost information could allow government agencies to set and review priorities for prevention on the basis of the financial impact of different injuries, in addition to their incidence or prevalence; and, accordingly, allow these government agencies to prioritise and therefore purchase injury prevention outputs across government ${ }^{5}$

- $\quad$ Cost information could provide an additional basis in allocating funding to growth industries ("picking winners")

- Better information on the costs of injuries could potentially justify the reallocation of current resources spent on injury prevention initiative and/or justify increased expenditure on injury prevention.
- Cost information could allow the government to identify:

long term cost savings for the government of injury prevention and rehabilitation initiatives, particularly for children (including impact on benefits and economic growth)

sustainablity and stability of cost of government interventions given population effects, etc.

- Cost information could allow the government to determine which industries have the highest injury costs, and therefore likely impediments on growth and investment.

- $\quad$ Gender specific injury cost information could allow the government to determine:

impact of injury on women, whether injured or carer

whether each gender is picking up the right costs relative to the incidence and impact in injury

extent of cross-subsidisation between genders

- Cost information could allow government to identify the extent to which the ACC Scheme is compensating claimants for the costs of injury, and to what extent these costs are being met through the benefit system ${ }^{6}$

- $\quad$ Cost information could allow the government to determine whether Pacific peoples are bearing disproportionate costs of injury, or are disproportionately affected-i.e. higher costs for same incidence

- Cost information allows the government to undertake cost-benefit analysis of transport safety initiatives

In addition, the needs analysis identified a widespread need for information on both economic and human costs of injuries, and for a range of policy perspectives including individual, household, wider family and whänau, employers, government, and society.

This suggests that the government's injury cost information needs are broad and extensive. The extent to which the costs of injury project will allow us to fill these information gaps will depend in part on available resources. By ensuring that the outcome from this project produces information is to address these types of questions, this project will have a significant impact on policy outcomes. 
Ministry of Transport, Maritime Safety Authority, Transfund, Ministry of Social Development, Department of Labour, Ministry of Health, Child, Youth and Family, Te Puni Kokiri, ACC, Statistics New Zealand, Civil Aviation Authority, Land Transport Safety Authority, Police, Ministry of Economic Development, Treasury, Ministry of Justice, Ministry of Women's Affairs, Ministry of Pacific Island Affairs

\section{Work in progress...}

This project is very much work in progress, and the specific or final outcome of the project has not yet been determined. Our project vision is to develop an agreed whole-of-govt approach to measuring the full costs of injury in NZ, which fills an identified information gap and is considered best practice across govt.

The initial objectives of the project were to:

- develop a general purpose method(s) for measuring costs of injury, which can be applied across govt agencies to inform decisions on injury prevention and rehabilitation interventions

- apply method(s) to produce estimates using currently available injury and costs data

There are a range of measurement approaches, notably the willingness to pay approach and the human capital approach. Different approaches, however, generate different information and are based on fundamentally different theoretical assumptions.

There is no consensus internationally about which approach to adopt - this depends on the purpose the information is needed for. Further work is therefore required before we can meet either of these objectives, including more detailed needs analysis, defining what is meant by "injury" for the purposes of this project, and data analysis.

\section{Costs of Injury Symposium}

The Department of Labour has recently hosted a Symposium to bring officials together to explore government agencies' costs of injury information needs, a range of approaches to measuring costs, and to debate a whole-of-government strategy for how best to improve injury costs information in New Zealand. The proceedings of this Symposium will shortly be available through the Department of Labour's website: http://www.dol.govt.nz

The primary outcome of the Symposium has been for us to initiate the development a Costs of Injury Strategy, with a much clearer vision of the outcome from this project. Strategy will also set up a work programme and will be undertaken by a mix of government projects and contract work. This should be completed by the end of March 2003.

\section{A New Zealand Injury Costs Database?}

One of the ideas floated at the Symposium was the concept of a New Zealand Injury Costs Database, similar to the Road Injury Costs Database developed in Australia. There was widespread interest in some form of injury costs database, but no consensus around what it would look like, how it would be developed, or how it would be managed and maintained.

The data-book, if developed, will most likely involve a mixture of data and models and be developed incrementally.

\section{Conclusion}

Our understanding of the impact of injury is severely limited because of a lack of basic information on costs of injury. Without this information, policy is in a partial vacuum in terms of both whether policy problems exist and their size.

The Social Consequences Research has provided us with an initial foray into this area by identifying some of the "costs" that occur and who bears them. The Costs of Injury project will take this one step further and help us identify the extent to which these, and other, costs can be measured and, to the extent practicable, provide us with one-off and (hopefully) ongoing estimates of costs.

\section{Further information}

\section{Jaimie Legge}

Labour Market Policy Group, Department of Labour

P O Box 3705, Wellington, NZ

Ph: (04) 9154037 Fax (04) 9154040

email: jaimie.legge@lmpg.dol.govt.nz

\section{Notes}

1. The views represented in this paper are the author's own and should not be taken to represent the views of the Department of Labour.

2. New Zealand Injury Data Review: April 2000 December 2001, Department of Labour and Statistics New Zealand, published October 2002. Available on the following website: http://www.statistics.govt.nz/injury

3. The Manager's functions are set out in s289 of the IPRC Act 2001 as: (a) to develop, set, publish, and maintain standards for the [management of injuryrelated information] after consultation with such 
persons or organisations as the Manager considers appropriate (b) to collect and aggregate injury-related information (c) to facilitate access (including by publishing) to injury-related information and unit record data (d) to consider and review current and future injury-related information requirements.

4. Further information is available on the following website: http://www.nzips.govt.nz
5. Note, however, that current gaps in injury information, including cost information, will not be addressed by the NZIPS per se. The co-ordination and dissemination of national injury data is a responsibility of the Injury Information Manager.

6. Note that the ACC legislation does not require ACC to compensate for the full costs of injury. 